\title{
RELAÇÃO ENTRE A SELIC E OS JUROS DAS TRÊS PRINCIPAIS MODALIDADES DE CRÉDITO DESTINADOS À PESSOA JURÍDICA
}

\author{
RELATIONS BETWEEN THE SELIC AND THE INTERESTS OF \\ THE THREE MAJOR CREDIT MODALITIES \\ FOR THE LEGAL ENTITY
}

Juliano Morais Galle ${ }^{1}$

Recebido em: 28/06/2016 Aceito em: 19/10/2016

juliano.galle@hotmail.com
Resumo: Foi analisada a relação entre a Selic e as três principais modalidades de crédito destinadas à pessoa jurídica no Brasil buscando distinguir essa relação durante períodos de alta e baixa na taxa Selic. Foram consideradas as taxas de juros das seguintes modalidades de crédito: Capital de Giro, Conta Garantida e Cheque Especial. O período analisado foi entre setembro de 2011 e abril de 2014, o qual iniciou com uma queda na Selic até fevereiro de 2013 seguido de alta até abril de 2014. Os resultados indicaram que há uma rigidez para baixo não significativa para a modalidade Capital de Giro. Para a modalidade Conta Garantida encontrou-se uma rigidez para cima também não significativa. Para a modalidade de Cheque Especial encontrou-se uma rigidez significativa para cima durante o período.

Palavras-chave: Política monetária. Pass-through de taxa de juros. Canal de taxa de juros.

Abstract: We analyze the relationship between the Selic and the three main types of credit destined to companies in Brazil seeking to distinguish this relationship during periods of high and low in the Selic rate. They were considered the interest rates of the following types of credit: Working Capital, Overdraft and Overdraft. The study period was between September 2011 and April 2014, which began with a drop in the Selic rate until February 2013 followed by high until April 2014. The results indicated that there is no significant downward rigidity for the Working Capital mode. For Overdraft mode found a stiffness up also not significant. For the Overdraft mode we found a significant stiffness up during the period.

Keywords: Monetary policy. Pass-through of interest rate. Money channel.

\footnotetext{
${ }^{1}$ Universidade Federal de Mato Grosso - UFMT - Cuiabá - Mato Grosso - Brasil.
} 


\section{INTRODUÇÃO}

O canal de taxa de juros como mecanismo de transmissão de política monetária reflete do impacto das taxas de juros do mercado monetário sobre o consumo e o investimento. Nesse contexto, uma política monetária de elevação das taxas de juros do mercado monetário influencia negativamente do consumo e o investimento da economia (MISHKIN, 1996). Uma hipótese para isso é que as taxas de juros do mercado de crédito acompanhem a taxa de juros do mercado monetário. O impacto da taxa básica de juros sobre as taxas de juros das modalidades de crédito em geral é conhecido como efeito pass-through. A análise do pass-through da taxa de juros, portanto, está intimamente relacionada ao canal de taxa de juros.

O objetivo desse trabalho é analisar a relação entre a Selic e as três principais modalidades de crédito destinadas à pessoa jurídica no Brasil buscando distinguir essa relação durante períodos de alta e baixa na taxa Selic. A análise compreende o período entre setembro de 2011 e abril de 2014 o qual iniciou com uma forte redução na Selic da casa dos 12\% em setembro de 2011 para a casa dos 7\% no início de 2013 e depois sofreu uma forte alta até cerca de 11\% em abril de 2014. Dessa forma, analisamos um período relativamente curto de tempo bem caracterizado inicialmente por uma política monetária de redução no juro seguido de uma política monetária contracionista de elevação na taxa básica de juros.

Os resultados indicaram que tanto durante a redução como durante a alta na Selic o efeito pass-through sobre o juro do crédito destinado ao financiamento de Capital de Giro foi praticamente o mesmo. O mesmo podemos dizer para a modalidade de crédito Conta Garantida. Contudo, para a modalidade Cheque Especial, durante o período de aumento da Selic houve uma forte rigidez para cima.

A justificativa de se compreender como as taxas de juros praticadas no mercado de crédito reagem frente a mudanças nas taxas básicas de juros se dá pela sua importância para os mecanismos de transmissão de política monetária que trazem para a economia real os efeitos dos choques monetários (BORIO e FRITZ, 1995).

\section{REVISÃO DA LITERATURA TEÓRICA}

A política monetária interfere na economia através de mecanismos de transmissão. Esses mecanismos, de forma simplificada, funcionam como canais que conduzem o choque de política monetária para a atividade econômica. Assim, quando o Banco Central adota uma política monetária, é através dos mecanismos de transmissão de política monetária que a economia sofrerá o choque monetário. De forma geral, os canais de transmissão da política monetária são cinco: (i) canal de taxa de juros, (ii) outros canais de preços de ativos, (iii) o canal do crédito, (iv) o canal de câmbio e o (v) canal de expectativas. O canal da taxa de juros pode ser simplificado ao apontar que um aumento na oferta de moeda implica na redução das taxas de juros reais. A redução dessas taxas, por sua vez, implica numa maior demanda por investimentos e bens duráveis. Vale ressaltar que, normalmente, os investimentos são financiados e implícitos ao custo do financiamento estão as taxas de juros reais. 
Da mesma forma, ocorre com os gastos em consumo de bens duráveis. Assim, a redução das taxas de juros reais reduz o custo de se realizar investimentos e consumir bens que serão pagos através de prestações. Portanto, como o aumento da oferta de moeda tende a reduzir a taxa de juros real, essa última tende a implicar num aumento do investimento e dos gastos em bens duráveis. Esses dois últimos contribuem para o aumento da demanda agregada da economia e também do produto. Mishkin (1996) mostra esquematicamente o funcionamento do canal de taxa de juros com base num modelo IS/LM simples:

$$
\mathrm{M} \uparrow \rightarrow \mathrm{i}_{\mathrm{r}} \downarrow \rightarrow \mathrm{I} \uparrow \rightarrow \mathrm{C} \uparrow \rightarrow \mathrm{Y} \uparrow
$$

Em que:

M é a oferta de moeda da economia, i são os juros reais de curto prazo, I e C representam o investimento e consumo, respectivamente e $\mathrm{Y}$ é o nível de produto de equilíbrio ${ }^{2}$.

Mishkin ainda ressalta que apesar de serem as taxas de juros reais de longo prazo que influenciam o consumo e o investimento e não as taxas de juros reais de curto prazo é possível afirmar que a taxa de juros real de longo prazo é determinada pela média das expectativas quanto ao futuro das taxas reais de curto prazo e, assim, variações nas taxas de juros reais de curto prazo provocam variações nas taxas de juros reais e longo prazo no mesmo sentido. Taylor (1995), corroborando Mishkin (1996), aponta que as taxas de juros de curto prazo, pelos modelos de estrutura a termo das taxas de juros, são significativas para determinar as taxas de juros de longo prazo no mesmo sentido.

Outra questão é que na conduta da política monetária o Banco Central interfere na taxa nominal de juros de curto prazo e não diretamente na taxa real de juros de longo prazo, a qual influencia as decisões de consumo e investimento. Sobre isso Taylor (1995), aponta que no curto prazo o ajustamento de preços será lento e manterá praticamente fixa a inflação esperada e assim o aumento da taxa de juro nominal provocará um aumento na taxa de juro real e esse efeito permanecerá até que as expectativas sejam ajustadas. Nesse sentido, por Mishkin (1996) e Taylor (1995), o canal de taxa de juros considera que ao alterar a taxa de juro nominal de curto prazo, o Banco Central acaba por interferir no mesmo sentido na taxa de juro real de longo prazo e essa última interfere nas decisões de investimento dos agentes econômicos.

Assim, o canal de taxa de juros possui uma hipótese implícita em sua estrutura de funcionamento: as taxas de juros do mercado monetário determinam de alguma forma as taxas de juros do mercado de crédito. Mais especificamente, teríamos:

$$
\mathrm{M} \uparrow \rightarrow \mathrm{i}_{\downarrow} \downarrow \rightarrow \mathrm{i}_{\mathrm{c} \downarrow} \rightarrow \mathrm{I} \uparrow \rightarrow \mathrm{C} \uparrow \rightarrow \mathrm{Y} \uparrow
$$

Em que:

$\mathrm{i}_{\mathrm{c}}$ representa as taxas de juros do mercado de crédito.

\footnotetext{
${ }^{2}$ Considerando que há sensibilidade do investimento com relação à taxa de juros.
} 
O presente artigo segue na seguinte sequência: (i) referencial teórico; (ii) revisão da literatura acerca do efeito pass-through; (iii) estatísticas descritivas e (iv) testes econométricos. Por último, são apresentadas as conclusões do artigo.

De forma geral, os estudos sobre a concentração e competição bancária no Brasil apontam para uma indústria cujo grau de concentração aumentou no final da década de 2000 e é, atualmente, moderado e não muito diferente do que se observa nos países de renda média e alta. Acerca da concorrência, os estudos também apontam que no Brasil o setor bancário não se comporta como um setor com concorrência perfeita, tampouco como um mercado cartelizado. Em termos de estrutura teórica de concorrência, aquela que mais se aproxima do caso brasileiro é a estrutura de concorrência de Bertrand (NAKANE e ROCHA, 2010).

Como referencial teórico microeconômico que explica o impacto da taxa do mercado monetário sobre as taxas praticadas no mercado de crédito utilizaremos o modelo de monopólio de Monti-Klein adaptado por Freixas e Rochet (2008) para uma competição monopolista. O lucro do banco é dado por:

$$
\pi(L, D)=\left(r_{l}(L)-r\right) L+\left(r(1-\alpha)-r_{D}(D)\right) D-C(D, L)
$$

Em que:

Tr é o lucro do banco, L é o volume de empréstimo, D é o volume de depósitos captados, r é a taxa de juros do mercado monetário ${ }^{3}, r_{L}$ é a taxa de juros dos empréstimos e $r_{D}$ é a taxa de juros dos depósitos.

O parâmetro $\alpha(0<\alpha<1)$ define a posição $\mathrm{M}$ do banco no mercado interbancário conforme $M=(1-\alpha) D-L$. A função $C(D, L)$ é a função custo do banco e é definida como:

$$
C(D, L)=\gamma_{D} D+\gamma_{L} L
$$

Num mercado com $\mathrm{n}$ bancos, das condições de maximização de lucro de cada banco podemos obter:

$$
\begin{aligned}
& \frac{\partial r_{L}}{\partial r}=\frac{1}{1-\frac{1}{N \varepsilon_{L}}}>0 \\
& \frac{\partial r_{D}}{\partial r}=\frac{1-\alpha}{1+\frac{1}{N \varepsilon_{D}}}>0
\end{aligned}
$$

Em que:

\footnotetext{
${ }^{3}$ Para simplificar, consideramos nesse modelo que os bancos captam recursos pagando a taxa do mercado monetário, ignorando, portanto, a existência da taxa do mercado interbancário que será considerada adiante. Podemos considerar também que a taxa do mercado interbancário é a mesma do mercado monetário.
} 
$\varepsilon_{L}>1$ e $\varepsilon_{D}>0$ representam, respectivamente, as elasticidades da demanda por empréstimos e oferta de depósitos com relação a suas respectivas taxas de juros.

Em termos teóricos, portanto, podemos esperar que as variações nas taxas de juros do mercado bancário, $r_{L}$, sigam no mesmo sentido as taxas de juros do mercado monetário, $r$. Esse modelo não contempla especificamente concentração de mercado e competição, somente o número $\mathrm{N}$ de bancos no mercado. Quando $\mathrm{N}=1$, o modelo trata de um monopólio e quando $\mathrm{N}=\infty$ trata de uma competição perfeita. Para a proposta desse trabalho que é mostrar os efeitos positivos de $r$ sobre $r_{L}$ ele é razoável. Iremos considerar que um valor baixo de $\mathrm{N}$ representa mercados altamente concentrados e pouco competitivos enquanto um valor alto de $\mathrm{N}$ representa mercados pouco concentrados e altamente competitivos.

Assim, pela simplificação teórica proposta, elevações nos juros do mercado monetário tendem a provocar elevação dos juros do mercado de crédito e a magnitude desse impacto depende basicamente de dois fatores: número de bancos no mercado, interpretado aqui como concentração/competição e elasticidade da demanda por empréstimos. Quanto maior é a concentração e menor a concorrência, baixo $\mathrm{N}$, e maior é a elasticidade dos empréstimos, $\varepsilon_{\mathrm{L}}$, menos sensível é a taxa de juros dos empréstimos, $\mathrm{r}_{\mathrm{L}}$, a mudanças na taxa de juros do mercado monetário, $\mathrm{r}$.

Pela teoria macroeconômica, o efeito pass-through das taxas do mercado monetário para as taxas do mercado de crédito pode ser esquematizado conforme a Figura 1.

Figura 1 - Esquema de Funcionamento do pass-through de taxas de juros

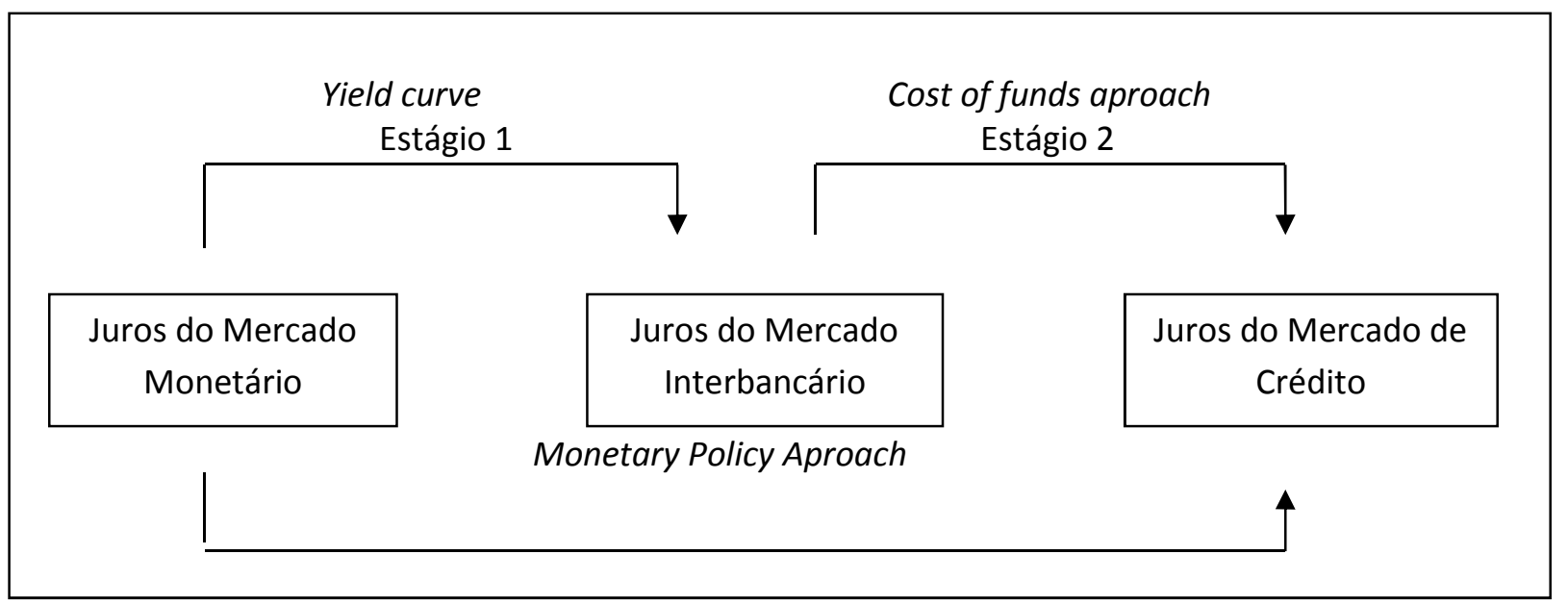

Fonte: Chirlesan e Apostoaie (2011, p.04)

Teoricamente, o efeito pass-through ocorre de duas formas: na primeira, ele pode ser dividido em dois estágios: (i) yield curve e (ii) cost of funds aproach. O primeiro estágio, yield curve, analisa o efeito dos juros da política monetária sobre os juros do mercado interbancário enquanto o segundo estágio, cost of funds aproach, analisa o efeito dos juros do mercado interbancário sobre os juros do mercado de crédito. Uma outra forma apresenta o efeito pass-through em apenas um estágio, o qual o impacto das taxas de juros do mercado monetário interfere diretamente as taxas de juros do mercado de crédito. Essa forma é conhecida na literatura como Monetary Policy Aproach. 
A diferença entre ambas está na capacidade da primeira distinguir os efeitos sobre os juros do mercado de crédito que são provenientes do mercado monetário dos efeitos que causados pelo mercado interbancário. Assim, é possível isolar o efeito dos juros da política monetária sobre os juros do mercado de crédito. Já na Monetary Policy Aproach isso não é possível de ser feito já que a análise não passa pelo mercado interbancário.

\section{REVISÃO DA LITERATURA EMPÍRICA}

Cottarelli e Kourelis (1994) analisam o impacto das taxas de juros do mercado monetário sobre as taxas de juros dos empréstimos bancários em 31 países desenvolvidos e em desenvolvimento. Os autores concluem que há diferença desse impacto nos países analisados e essas diferenças ocorrem por conta de cinco fatores estruturais: (i) a existência de um mercado de curto prazo que opera com títulos públicos e é significativo em se tratando de política monetária, (ii) restrições a movimentos de capital, (iii) restrições a competição bancária; (iv) a magnitude das instituições privadas no sistema bancário e (v) a contenção do componente aleatório da taxa de juros do mercado monetário. Esse último ao dificultar que os bancos identifiquem variações duráveis nas taxas de juros do mercado monetário. Cottarelli e Kourelis (1994) afirmam ainda que as políticas de privatização interferem nas respostas das taxas de empréstimos bancários às mudanças nas taxas do mercado monetário, isso porque bancos privados são mais eficientes e menos sujeitos às influências políticas. Além disso, as respostas das taxas de juros bancárias aos movimentos dos juros do mercado monetário são menores em países com inflação elevada. Donnay e Degryse (2001), De Bondt (2005), Toolsema et al. (2001), Borio e Fritz (1995) e Mojon (2000), também abordando principalmente países da zona do euro, apontam para as diferenças entre as respostas das taxas de juros do sistema bancários às variações nos juros do mercado monetário em vários países.

Já o trabalho de Dale (1993) analisa o impacto das taxas de juros do mercado monetário sobre as taxas de juros de mercado bancário considerando diversas maturidades. Seus dados são referentes ao Reino Unido e remetem o período de 1987 a 1993 e suas conclusões apontam que a taxa de juros do mercado monetário influencia as taxas de juros do mercado bancário com maturidade entre 1 mês e 5 anos. Segundo o autor, as taxas de juros de longo prazo são influenciadas pela expectativa das taxas de juros de curto prazo e, assim, pelos níveis correntes das taxas de juros oficiais (do mercado monetário). Kaketsis e Sarantis (2006), utilizando um modelo semelhante ao de Dale (1993) concluíram que mudanças nas taxas de juros oficiais provocaram mudanças nas taxas de juros de curto e médio prazo do mercado bancário durante os anos 90 .

Weth (2002) analisa o efeito pass-through para a economia alemã entre abril de $1993 \mathrm{e}$ dezembro de 2000. Entre outras conclusões, mostrou que grandes instituições financeiras ajustam suas taxas mais rapidamente que as pequenas e que os bancos que utilizam mais depósitos de poupança como fonte de recursos ajustam suas taxas mais lentamente.

Berstein e Fuentes (2003) estimam um modelo semelhante ao de Weth (2002) para a economia chilena entre 1996 e 2002 considerando também o tamanho dos bancos, o perfil dos clientes e os níveis de risco. As conclusões de Berstein e Fuentes (2003) apontam que o tamanho 
dos bancos, a proporção de empréstimos vencidos e a proporção de consumidores domésticos aumentam as respostas das taxas de juros do mercado bancário frente a mudanças nas taxas de juros do mercado interbancário.

Ausubel (1991) analisa a rigidez para baixo das taxas de juros dos cartões de crédito da economia norte-americana durante a década de 1980. O questionamento do autor era acerca do porque as taxas de juros dos cartões de crédito não acompanhavam a queda das taxas de juros do mercado interbancário (cost of funds) sendo que competiam 4000 firmas. A conclusão foi que os tomadores de crédito não respondiam a redução nos juros e eram adimplentes mesmo com os altos juros dos cartões de crédito, aumentando a lucratividade das instituições financeiras.

Alencar (2003), que também utiliza um modelo semelhante ao de Weth (2002), analisa o efeito pass-through na economia brasileira entre abril de 1999 a setembro de 2003. O autor considera as taxas de juros médias do crédito destinado a pessoas físicas e jurídicas bem como as taxas de algumas modalidades específicas como Hot Money, Conta Garantida, Capital de Giro, entre outras. Algumas de suas conclusões são: (i) na maioria dos casos, o grau de transmissão da Selic para as taxas do mercado de crédito é completa no longo prazo; (ii) no curto prazo, o efeito pass-through é maior para empréstimos a pessoas físicas do que para pessoas jurídicas; (iii) não pode-se afirmar que o pass-through é menor quanto maior for os prazos das operações.

Castro e Mello (2010) buscam mostrar se as taxas dos empréstimos respondem mais a elevações que a reduções da taxa Selic para as modalidades de crédito livre destinadas a pessoa física entre junho de 2000 e abril de 2006. Seus resultados apontaram que o efeito pass-through da Selic para as taxas dos empréstimos bancários são menores quando há uma queda na Selic do que quando há uma elevação, resultando assim numa assimetria do repasse das taxas de juros. No presente trabalho, diferenciando de Castro e Mello (2010), o objeto de estudo foi o crédito destinado à pessoa jurídica.

\section{DESCRIÇÃO DOS DADOS UTILIZADOS}

Será analisado o efeito pass-through para três séries referentes aos juros do crédito destinado à pessoa jurídica: Capital de Giro, Conta Garantida e Cheque Especial. As três modalidades são empréstimos de curto prazo e buscam solucionar problemas de caixa das empresas. A Conta Garantida e o Cheque Especial são empréstimos do tipo rotativo. A principal diferença entre eles é que a Conta Garantida estipula um prazo para quitação do crédito enquanto o Cheque Especial não exige quitação do valor emprestado possibilitando que a dívida seja rolada por um longo período. Os empréstimos para Capital de Giro não são do tipo rotativo e se configuram de várias formas, normalmente, como empréstimos que são pagos em prestações finitas.

A soma dessas três modalidades equivale, na média, a $55 \%$ do total do crédito destinado à pessoa jurídica entre setembro de 2011 e abril de 2014. Na escolha do período contemplou-se uma primeira fase de baixa da Selic até dezembro de 2012 seguida de uma fase de alta, até abril de 2014. 
Dessa forma, pretendeu-se captar o efeito pass-through num período de alta dos juros e em um período de queda ${ }^{4}$ não considerando, portanto, os períodos de mais estabilidade da Selic.

Tabela 1 - Concessão de crédito (em $\mathrm{R} \$$ milhões)

\begin{tabular}{lccc}
\hline \hline Modalidade de Crédito & Média & $\%$ & $\% \mathbf{A C}$ \\
\hline RLPJ - Total & 122.589 & $100,0 \%$ & \\
RLPJ - Capital de giro total & 26.344 & $21,5 \%$ & $21,5 \%$ \\
RLPJ - Conta garantida & 21.959 & $17,9 \%$ & $39,4 \%$ \\
RLPJ - Cheque especial & 19.212 & $15,7 \%$ & $55,1 \%$ \\
RLPJ - Desconto de duplicatas & 10.231 & $8,3 \%$ & $63,4 \%$ \\
RLPJ - Adiantamento sobre contratos de câmbio (ACC) & 7.568 & $6,2 \%$ & $69,6 \%$ \\
RLPJ - Compror & 7.113 & $5,8 \%$ & $75,4 \%$ \\
RLPJ - Desconto de cheques & 4.177 & $3,4 \%$ & $78,8 \%$ \\
RLPJ - Cartão de crédito total & 3.820 & $3,1 \%$ & $81,9 \%$ \\
RLPJ - Outros & 22.165 & $18,1 \%$ & $100,0 \%$ \\
\hline \hline
\end{tabular}

Fonte: Banco Central do Brasil. Outras taxas: Outros créditos livres (9,1\%), Antecipação de faturas de cartão de crédito (2,2\%), Financiamento a exportações $(2,1 \%)$, Vendor $(1,7 \%)$, Aquisição de bens total $(1,3 \%)$, Repasse externo $(0,7 \%)$, Arrendamento mercantil $(0,4 \%)$ e Financiamento a importações $(0,5 \%)$.

As estatísticas das séries, na tabela 2, evidenciam a magnitude das taxas de juros no período analisado, bem como seus desvios padrão, valores máximos e mínimos. A taxa de juros do Cheque Especial destinado à pessoa jurídica, com uma média de 155 pontos percentuais no período, é a modalidade dentre as consideradas aqui com maior percentual. A Taxa Selic, como já era esperado, possui a menor média no período analisado. A taxa de juros dos empréstimos para capital de giro, apesar de na média ser menor que a taxa da Conta Garantida possui um desvio padrão maior.

Tabela 2 - Estatística das Séries

\begin{tabular}{llccccc}
\hline \hline & Denominação & Obs & Méd & D.P. & Mín & Máx \\
\hline 4189 & Selic & 32 & 9,02 & 1,55 & 7,11 & 11,91 \\
\hline 20725 & $\begin{array}{l}\text { RLPJ Capital de giro } \\
\text { total }\end{array}$ & 32 & 18,64 & 2,35 & 15,05 & 22,53 \\
\hline 20726 & RLPJ Conta garantida & 32 & 38,11 & 1,24 & 36,05 & 40,33 \\
\hline 20727 & $\begin{array}{l}\text { RLPJ Cheque } \\
\text { especial }\end{array}$ & 32 & 155,43 & 10,60 & 143,11 & 174,37 \\
\hline \hline
\end{tabular}

Fonte: Elaborado pelo autor. Todos os dados em \% a.a.

\footnotetext{
${ }^{4} \mathrm{~A}$ periodicidade das séries referentes à Conta Garantida e ao Cheque Especial somente estão disponíveis a partir de março de 2011. Até agosto de 2011, isto é, durante seis meses houve um aumento na Selic e entre maio e outubro de 2014 a taxa Selic permaneceu praticamente em 10,9 pontos percentuais. Optou-se por desconsiderar nos testes o aumento da Selic entre março e agosto de 2011 e a partir de maio de 2014. A manutenção do valor da Selic nesse segundo período não é interessante em termos de análise do efeito pass-through.
} 
Pelos gráficos da figura 2, 3 e 4, as taxas de juros da Conta Garantida e dos financiamentos para capital de giro acompanham a Selic ao longo do tempo. Contudo, parece que há uma diferença de comportamento entre o período em que há aumento e o período em que há redução na Selic para os juros do cheque especial. Durante as variações positivas na Selic, parece que houve uma variação positiva nos juros do cheque especial numa proporção menor do que quando houve uma redução da Selic e mesmo num período de certa manutenção da Selic em pouco mais de sete pontos percentuais continuou havendo uma queda dos juros dessa modalidade de crédito.

Figura 2 - Juros da modalidade Capital de Giro

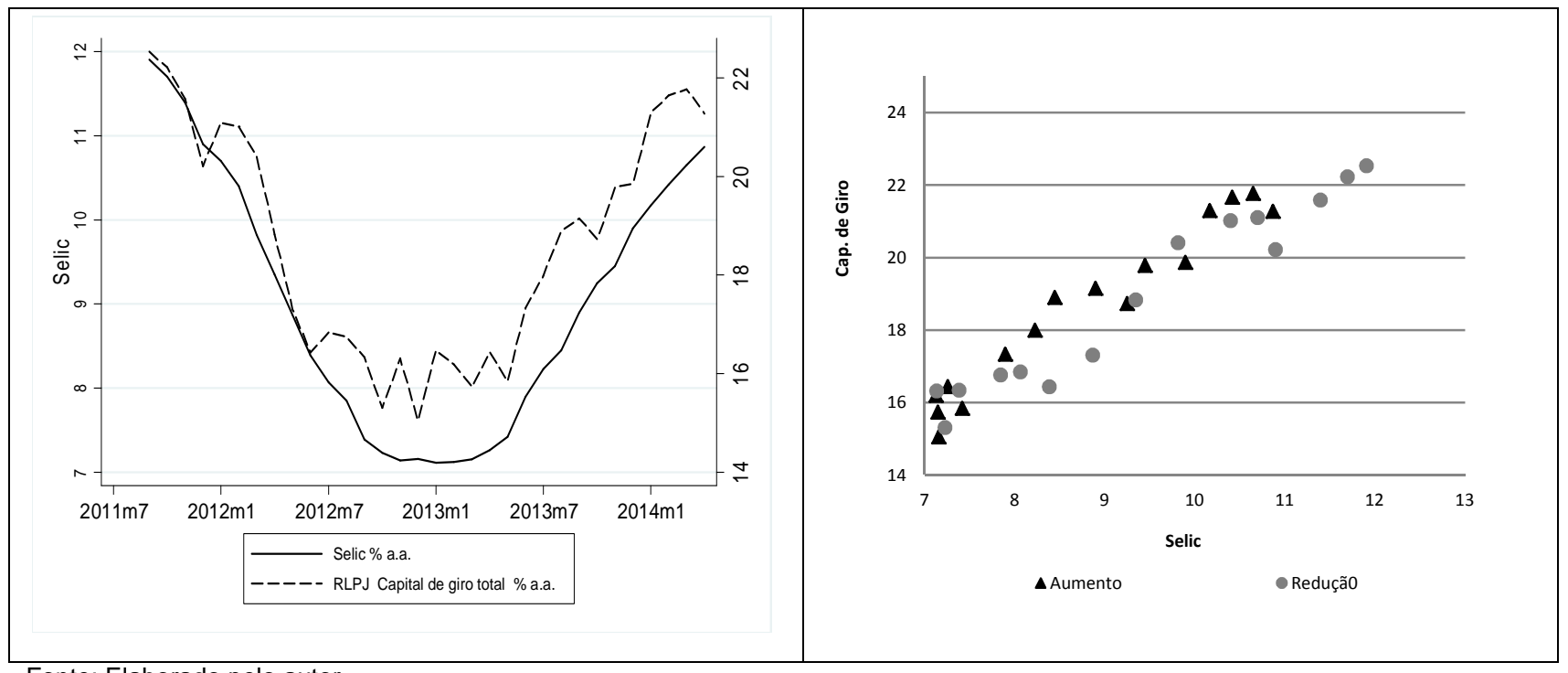

Fonte: Elaborado pelo autor.

Figura 3 - Juros da modalidade Conta Garantida

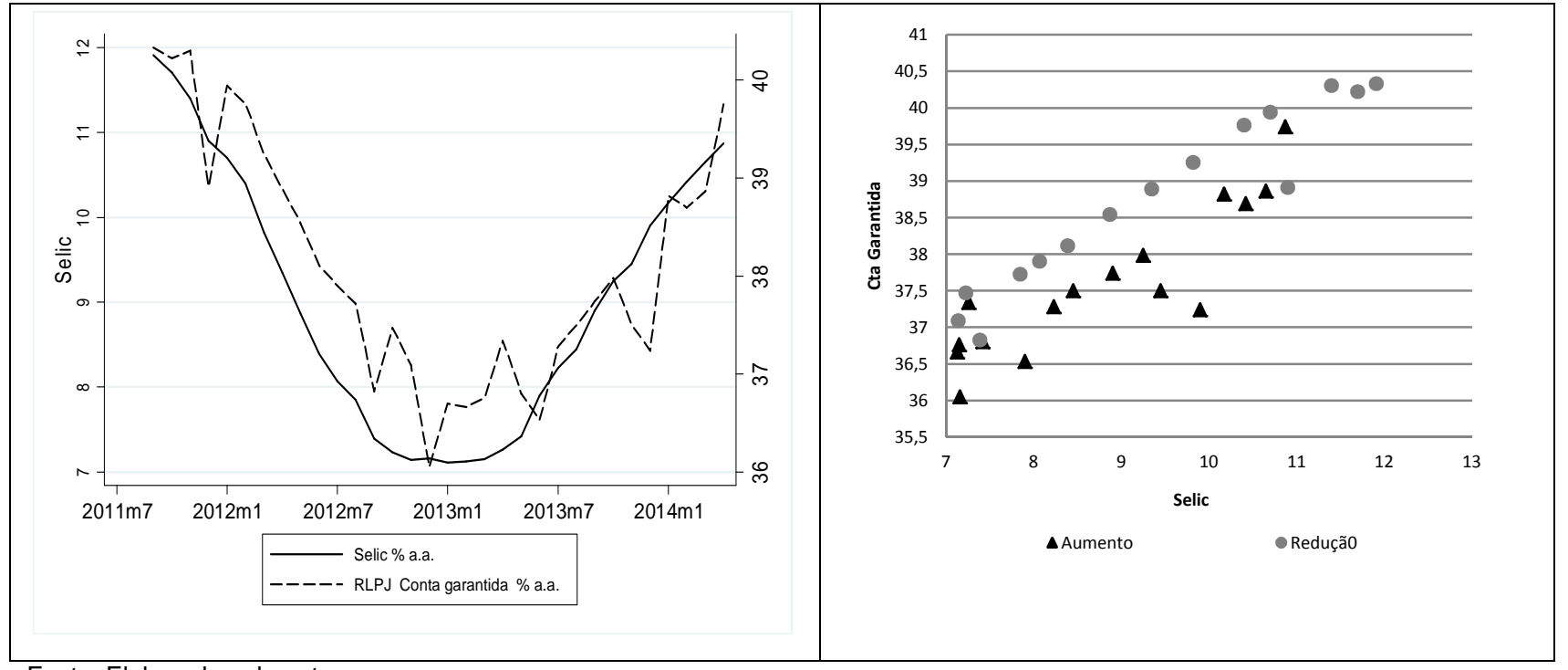

Fonte: Elaborado pelo autor.

Estudos do CEPE [ISSN 1982-6729]. Santa Cruz do Sul, n. 44, p. 68-83, jul./dez. 2016. 
Figura 4 - Juros da Modalidade Cheque Especial

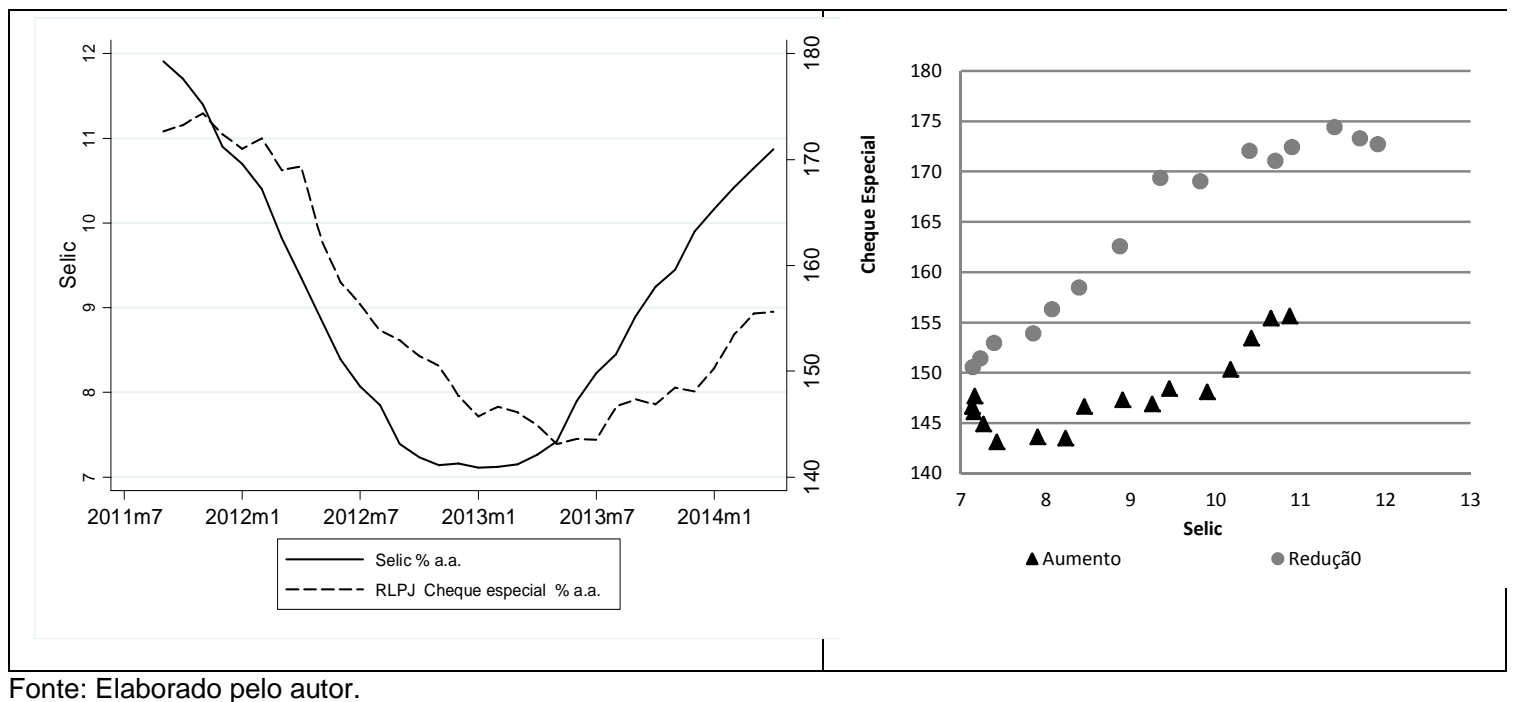

Os pontos do gráfico de dispersão são separados em períodos de aumento e redução da Selic. O objetivo é verificar se durante o aumento da Selic os repasses para os juros do mercado de crédito tiveram a mesma magnitude que durante as reduções. Para a modalidade Capital de Giro, parece haver mesmo um repasse e para a modalidade Conta Garantida isso não fica claro. Para os juros do Cheque Especial, parece claro que os repasses durante a redução da Selic foram maiores do que os repasses durante o aumento.

As tabelas abaixo apresentam a correlação entre os juros das modalidades de crédito aqui consideradas e a taxa Selic. As correlações para a taxa de juros referente aos empréstimos para Capital de Giro giram em torno de 0,96 e 0,97 em todo período, assim como nos períodos de alta e nos períodos de baixa na Selic. Os juros da conta garantida apresentam uma correlação maior com a Selic nos momentos de queda na Selic e o mesmo vale para os juros do cheque especial. Um resultado mais acentuado ainda é apresentado para os juros do Cheque Especial: durante o aumento da Selic a correlação foi de 0,8036 e durante a queda foi de 0,9662 .

Tabela 3 - Correlação

\begin{tabular}{c|c|c}
\hline \hline Capital de Giro & Conta Garantida & Cheque Especial \\
\hline \multicolumn{3}{c}{ Em todo período } \\
\hline 0,9623 & 0,9039 & 0,7294 \\
\hline \multicolumn{3}{|c}{ Redução da Selic $(\Delta<0)$} \\
\hline 0,9654 & 0,9602 & 0,9662 \\
\hline 0,9735 & Aumento da Selic $(\Delta \geq 0)$ \\
\hline \hline
\end{tabular}

Fonte: Elaborado pelo autor 


\section{METODOLOGIA E TESTES ECONOMÉTRICOS PARA O EFEITO PASS-THROUGH}

Os dados analisados no presente trabalho, como apontado anteriormente, contemplam o período entre setembro de 2011 até dezembro de 2014 em encontra-se em periodicidade mensal totalizando 32 observações conforme a tabela 1.

Foi testada a estacionariedade das séries e concluído que tanto a Selic quanto a série dos juros da Conta Garantida são estacionários em terceira diferença enquanto as séries referente aos juros das modalidades Capital de Giro e Cheque Especial são estacionárias em segunda diferença .

Tabela 4 - Testes de Estacionariedade

\begin{tabular}{l|c|c|c|c}
\hline \hline & Selic & Capital de Giro & Conta Garantida & $\begin{array}{c}\text { Cheque } \\
\text { Especial }\end{array}$ \\
\hline Em nível & $-1,868$ & $-1,391$ & $-0,926$ & $-1,933$ \\
\hline $1^{\text {a }}$ Diferença & $-0,923$ & $-2,677$ & $-2,623$ & $-2,125$ \\
\hline $2^{\text {a }}$ Diferença & $-1,990$ & $-5,578^{\star \star *}$ & $-1,911$ & $-5,526^{\star \star \star}$ \\
\hline $3^{\circ}$ Diferença & $-6,940^{* \star *}$ & - & $-3,060^{\star *}$ & - \\
\hline \hline
\end{tabular}

Obs: todos os testes econométricos foram realizados no software Stata.

Os testes econométricos compreendem a regressão por Mínimos Quadrados Ordinários da equação:

$$
r_{i, t}=\alpha_{1, i}+\alpha_{2, i} 1(\Delta \text { Selic } \geq 0)+\beta_{1, i} m_{t}+\beta_{2, i} \operatorname{Selic} 1(\Delta \text { Selic } \geq 0)+\text { pmacro }_{i, t}+e_{i, t}
$$

Onde $r_{i, t}$ refere-se aos juros do crédito, $m_{t}$ refere-se aos juros do mercado monetário (taxa Selic). Na equação, macro $_{t}$, refere-se a um vetor das seguintes variáveis de controle: PIB mensal em milhões, IPCA em percentual ao mês, desemprego nas regiões metropolitanas, indicador $\mathrm{EMBI}+\mathrm{da}$ JP Morgan e as taxas de inadimplência de cada modalidade de crédito analisada ${ }^{5}$.

A definição do modelo e da escolha das variáveis de controle foi inspirada em Castro e Mello $(2010)^{6}$. Foi inserida a variável PIB para captar o efeito da atividade econômica. A taxa de inflação, medida pelo IPCA, busca captar os efeitos tanto sobre a política monetária quanto sobre as taxas nominais cobradas pelas instituições financeiras. Foi inserida a taxa de desemprego buscando captar os efeitos da atividade econômica sobre a demanda por crédito e o indicador $\mathrm{EMBI}+$ busca controlar os efeitos dos choques externos. A taxa de inadimplência da modalidade de crédito específica também é incluída como variável de controle. Ainda seguindo Castro e Mello (2010), aumentos na taxa básica podem influenciar a inadimplência e, portanto, pode haver correlação entre inadimplência e taxa Selic, principalmente em nível agregado. Porém os próprios autores apontam que em nível

\footnotetext{
${ }^{5}$ Os testes foram realizados com as primeiras diferenças de todas as variáveis de controle que são I(1). Na codificação do Banco Central são as séries 4380, 433, 10777, respectivamente, 21093 para a inadimplência dos empréstimos destinados a capital de giro, 21094 para os empréstimos da modalidade Conta Garantida e 21095 para o Cheque Especial.

6 Defasagens não foram incluídas porque os bancos fixam as taxas de juros com base nos valores contemporâneos das variáveis consideradas. As taxas de juros são referentes a novas concessões e não ao estoque de crédito da carteira dos bancos. Nesse último caso, a geração da série poderia ser influenciada por valores defasados.
} 
desagregado esse efeito não é tão claro e que a inadimplência pode ser considerada exógena pela existência de uma defasagem entre a concessão de crédito e a contabilização da inadimplência, que ocorrerá um tempo após a ocorrência o vencimento. Caso o modelo aqui utilizado estivesse utilizando defasagens essa última consideração poderia ser refutada.

As variáveis dummy, inseridas para captar diferenças de intercepto e inclinação, buscam verificar se o efeito de aumento da Selic sobre os juros do crédito são maiores do que os efeitos da queda.

Tabela 5 - Resultados das regressões de MQO

\begin{tabular}{|c|c|c|c|c|c|c|}
\hline & $\begin{array}{l}\text { Capital de } \\
\text { Giro }\end{array}$ & $\begin{array}{c}\text { Capital de } \\
\text { Giro }\end{array}$ & $\begin{array}{c}\text { Conta } \\
\text { Garantida }\end{array}$ & $\begin{array}{c}\text { Conta } \\
\text { Garantida }\end{array}$ & $\begin{array}{l}\text { Cheque } \\
\text { Especial }\end{array}$ & $\begin{array}{l}\text { Cheque } \\
\text { Especial }\end{array}$ \\
\hline \multirow[t]{2}{*}{$\alpha_{1, i}$} & 5,73 & 5,95 & 32,08 & 31,86 & 111,97 & 108,96 \\
\hline & $(0,000)$ & $(0,000)$ & $(0,000)$ & $(0,000)$ & $(0,000)$ & $(0,000)$ \\
\hline \multirow[t]{2}{*}{$\alpha_{2, i}$} & $-1,49$ & $-1,53$ & $-0,21$ & 0,10 & 15,24 & 19,20 \\
\hline & $(0,247)$ & $(0,267)$ & $(0,821)$ & $(0,913)$ & $(0,013)$ & $(0,007)$ \\
\hline \multirow[t]{2}{*}{$\beta_{1, i}$} & 1,40 & 1,37 & 0,71 & 0,72 & 5,49 & 5,85 \\
\hline & $(0,000)$ & $(0,000)$ & $(0,000)$ & $(0,000)$ & $(0,000)$ & $(0,000)$ \\
\hline \multirow[t]{2}{*}{$\beta_{2, i}$} & 0,23 & 0,24 & $-0,05$ & $-0,08$ & $-3,12$ & $-3,58$ \\
\hline & $(0,108)$ & $(0,118)$ & $(0,605)$ & $(0,459)$ & $(0,000)$ & $(0,000)$ \\
\hline $\begin{array}{c}\text { Variáveis de } \\
\text { Controle }\end{array}$ & Não & Sim & Não & Sim & Não & Sim \\
\hline $\mathrm{R}^{2}$ Ajustado & 0,9406 & 0,9420 & 0,8841 & 0,8902 & 0,9381 & 0,9299 \\
\hline Durbin-Watson & 1,89 & 2,12 & 1,74 & 2,19 & 1,23 & 1,29 \\
\hline $\begin{array}{c}\text { Normalidade }^{1} \text { de } \\
e_{i, t}\end{array}$ & 0,2731 & 0,7089 & 0,0677 & 0,3691 & 0,9355 & 0,9487 \\
\hline $\begin{array}{c}\text { Estacionariedade }^{2} \\
\text { de } e_{i, t}\end{array}$ & $-1,732$ & $-3,776^{* * *}$ & $-3,993^{* * *}$ & $4,187^{\star * *}$ & $-2,763^{*}$ & $-2,572$ \\
\hline $\begin{array}{l}\text { Teste de } \\
\text { Ramsey }\end{array}$ & 0,5799 & 0,4722 & 0,5715 & 0,8280 & 0,000 & $(0,000)$ \\
\hline Breusch-Pagan $^{4}$ & 0,6296 & 0,2691 & 0,6875 & 0,4813 & 0,3021 & 0,4859 \\
\hline $\begin{array}{l}\text { Obs.: p-valor entre par } \\
\text { defasagem } \mathrm{Ng} \text {-Perron } \\
\text { Fuller com o maior núm } \\
\text { erro tipo I (rejeitar } \mathrm{H}_{0} \\
\text { estacionária. Em outras } \\
\text { maior a favor do encont } \\
\text { resíduos em regressões } \\
\text { Breusch-Pagan/Cook-W }\end{array}$ & $\begin{array}{l}\text { nteses. (1) Pro } \\
\text { equencial } t \text {, Sch } \\
\text { ero de defasage } \\
\text { uando ela for v } \\
\text { palavras, realiza } \\
\text { o da não estaci } \\
\text { com séries tem } \\
\text { eisberg para } \mathrm{H} 0 \text { : }\end{array}$ & $\begin{array}{l}>X^{2} \text { para o } \\
\text { warz (SIC) e Al } \\
m \text { sugerido ent } \\
\text { erdadeiro), ou } \\
\text { ndo os testes D } \\
\text { nnariedade. A a } \\
\text { porais. (3) Prob } \\
\text { variância const }\end{array}$ & $\begin{array}{l}\text { ste de assimet } \\
\text { ike modificado } \\
\text { os três critério } \\
\text { ja, rejeitar a na } \\
\text { key-Fuller com } \\
\text { ção desse "rige } \\
F \text { para } H_{0} \text { : nã } \\
\text { te. }\end{array}$ & $\begin{array}{l}\text { curtose; (2) } \\
\text { Ng-Perron ( } \\
\text { uscando minin } \\
\text { estacionarieda } \\
\text { maior númerc } \\
\text { se deu pela im } \\
\text { lá variáveis on }\end{array}$ & $\begin{array}{l}\text { tre os critéri } \\
\text { ), foi realizac } \\
\text { a probabilid } \\
\text { quando na v } \\
\text { defasagens, } \\
\text { tância da est } \\
\text { as; (4) Prob }\end{array}$ & $\begin{array}{l}\text { seleção de } \\
\text { teste Dickey- } \\
\text { de cometer o } \\
\text { de ela é não } \\
\text { obabilidade é } \\
\text { lariedade dos } \\
\text { para o teste }\end{array}$ \\
\hline
\end{tabular}

Os coeficientes das regressões onde estão incluídas as variáveis de controle apontam que, no período de queda da Selic, cada ponto percentual a menos implica em 1,37 ponto percentual a 
menos nos juros da modalidade Capital de Giro. O coeficiente $\beta_{2, i}$ é positivo e não significativo implicando que o aumento de um ponto percentual da Selic também é seguido por um aumento praticamente igual a 1,37 ponto percentual do juro dos empréstimos para capital de giro. Resultado semelhante é encontrado para os juros da modalidade de Capital de giro: para cada ponto percentual de aumento (queda) na Selic, há um aumento (queda) de 0,72 pontos percentuais nos juros dessa modalidade de crédito. Já para os juros do Cheque Especial encontrou-se rigidez para cima durante o período de aumento na Selic: enquanto a queda de um ponto percentual na Selic era acompanhada por uma queda de 5,85 pontos percentuais nos juros dessa modalidade de crédito, durante a alta da Selic, cada ponto percentual era seguido por um aumento de 2,27 [5,85-3,58] pontos percentuais.

Esses resultados sugerem que o repasse da taxa básica de juros para do da modalidade Capital de Giro foi mais acentuada durante o período de contração monetária sugerindo que há certa rigidez para baixo nas taxas de juros dessa modalidade de crédito. Essa rigidez, quando ocorre para baixo, pode ser relacionada a tomadores de crédito pouco sensíveis às taxas de juros como apontado por Ausubel (1991): mesmo durante uma queda das taxas básicas de juros os agente ainda estão dispostos a pagar uma taxa de juros praticamente constante na captação de crédito. Podemos supor que o mercado entende que a redução das taxas de juros do financiamento para capital de giro por parte de algumas instituições não provoca um direcionamento dos tomadores de empréstimos para essas instituições. Isso pode ocorrer por falta de informação dos captadores de crédito sobre as taxas praticadas no mercado, pela dificuldade em termos burocráticos de mudar de fonte de recursos para emprestar para capital de giro ou pelos custos de não fidelização à uma instituição financeira.

Para a Conta Garantida, há maior correlação com a Selic durante a queda dessa última. Há também uma pequena rigidez para cima que não se mostrou significativa. Dessa forma, podemos afirmar que o efeito pass-through teve a mesma magnitude tanto durante a alta quanto durante a baixa da taxa básica de juros. Como as dummies de inclinação e intercepto para o período de alta na Selic não foram significativas e o estacionariedade dos resíduos foi significativa à $1 \%$, podemos afirmar que os juros da Conta Garantida e da Selic são séries cointegradas no período analisado.

No caso dos juros do Cheque Especial, há uma correlação bem maior com a Selic no período de Política Monetária expansiva do que no período de elevação nas taxas de juros. Os testes mostraram forte rigidez para cima durante o período de aumento na Selic. Nesse caso, podem estar envolvidas questões de seleção adversa no sentido de Stiglitz e Weiss (1981): um aumento nas taxas de juros possivelmente aumentaria a demanda por crédito de tomadores duvidosos elevando a inadimplência e reduzindo a lucratividade da instituição financeira. Por causa disso, a instituição opta por não repassar os aumentos das taxas de juros do mercado monetário para as taxas de juros do mercado de crédito. Podemos ainda esperar que por causa da magnitude dos juros do Cheque Especial, acima dos $140 \%$ a.a., os clientes evitem utilizar o Cheque Especial das instituições com maiores taxas. Como o Cheque Especial é uma modalidade de crédito normalmente vinculada à uma Conta Corrente e é normal o empresário possuir Conta Corrente em mais de uma instituição financeira, não fica difícil para ele utilizar o Cheque Especial daquela instituição que cobre uma taxa de juros menor. Há uma menor fidelização, portanto, para essa modalidade de crédito. 
Assim, no caso específico do Cheque Especial, durante o período de contração da Política Monetária o efeito pass-trought apresenta uma rigidez para cima. Isso pode ocorrer segundo Stiglitz e Weiss (1981) porque os agentes emprestadores buscam as menores taxas de juros no mercado e as instituições que repassam "completamente" o aumento das taxas básicas de juros acabam atraindo os tomadores de crédito com um risco de inadimplência maior. Esses fatores, portanto, explicariam a rigidez para cima das taxas de juros do Cheque Especial destinado à pessoa jurídica.

\section{CONCLUSÃo}

Logo na introdução, foi apresentada a importância do efeito pass-through para o funcionamento do canal de juros de transmissão da Política Monetária. Posteriormente, já na primeira parte do trabalho, foi realizada uma abordagem teórica mostrando os argumentos microeconômicos e macroeconômicos a favor da existência do efeito pass-through na economia. Em termos microeconômicos, foi mostrado que o número de instituições financeiras concorrentes no mercado bem como as elasticidades-juro da demanda por crédito são fatores que determinam a magnitude desse efeito. Em termos macroeconômicos foi apontado que o efeito pass-through ocorre de duas formas: (i) yield curve seguido do cost of funds aproach e (ii) Monetary Policy Aproach.

Posteriormente, foi realizada uma revisão da literatura acerca do efeito pass-through tanto na economia brasileira como para outras economias.

Tanto as análises descritivas como os testes econométricos realizados indicaram a existência do efeito de repasse da taxa básica de juros para os juros das três modalidades de crédito destinadas à pessoa jurídica consideradas no trabalho: Capital de Giro, Conta Garantida e Cheque Especial. Especificamente para a modalidade Cheque Especial houve certa rigidez para cima e os aumentos dos juros dessa modalidade de crédito não acompanharam a Selic na mesma magnitude que no período anterior, quando houve uma queda. Uma possível explicação para isso é que durante os aumentos das taxas de juros os tomadores de crédito via Cheque Especial procuram as melhores taxas de juros do mercado e isso provoca rigidez para cima das taxas de juros dessa modalidade de crédito. 


\section{REFERÊNCIAS}

ALENCAR. L. S., O Pass-Through da Taxa Básica: Evidências para as Taxas de Juros Bancárias. Relatório de Economia Bancário e Crédito. Banco Central do Brasil. p.93-103, 2003.

AUSUBEL, L. The Failure of Competition in the Credit Card Markets. The American Economic Review, 81(1), 50-81, 1991

BANCO CENTRAL DO BRASIL, Séries Temporais, Disponível em http://www.bcb.gov.br. Acesso em: 10 out. 2014.

BERSTEIN, S.; FUENTES. R., From Policy Rate to Bank Lending Rates: The Chilean Banking Industry", LACEA Papers and Proceedings, Puebla, México, 30p., 2003.

BORIO, C.; FRITZ, W., The Response of Short-Term Lending Rate to Policy Rates: A Cross Country Perspective, Texto para discussão n. 27, Banco de Compensações Internacionais, Basiléia, 1995.

CASTRO, P. H. R. de; MELLO, J. M. P. de, Existe assimetria no repasse dos juros bancários a variações na taxa Selic?. 2010. Apresentado no 38. Encontro Nacional de Economia da Anpec, Salvador, 2010.

CHIRLESAN, D.; APOSTOAIE, M.C., The Interest Rate Pass-through from Policy Rates to Interbank Interest Rates in the Romanian Financial System, Working Paper, Forum for Research in Empirical International Trade, 2011.

COOK, T e HAHN, T., The Effect of Changes in the Federal Funds Rate Target on Market Interest Rates in the 1970s, Journal of Monetary Economics, vol. 24, n 3, p. 331-351, 1989.

DE BONDT, G., Interest Rate Pass-Through: Empirical Results for the Euro Area, German Economic Review, v. 6, n.1, p. 37-78, 2005.

DONNAY, M.; DEGRYSE. H., Bank Lending Rate Pass-through and Differences in the Transmission of a Single EMU Monetary policy, Texto para Discussão 01.17, Centro de Estudos Econômicos, Universidade Católica de Leuven, 2001.

DALE, S., Effects of changes in official UK rates on market rates since 1987, Manchester School, vol. 61 (Supplement), p. 76-94, 1993.

HILL, R, C.; GRIFFITHS, W. E.; JUDGE, G. G., Econometria, 2 ed., São Paulo: Saraiva, 2006.

HOFMAN, B. ;MIZEN, P., Interest Rate Pass-Through and Monetary Transmission: Evidence from Individual Financial Institutions retail Rates, Economica, vol. 71(281), p. 99-123, 2004.

KAKETSIS, A. e SARANTIS, N., The Effects of Monetary Policy Changes on MarketInterest Rates in Greece: An Event Study Approach, International Review of Economics and Finance, vol. 15, p. 487-504, 2006.

MISHKIN, F., The Channels of Monetary Transmissions: lessons for monetary policy, Banque de France Bulletin Digest, no. 27. Mar, 1996.

MOJON, B. Financial Structure and the Interest Rate Channel of ECB Monetary Policy. European Central Bank Working Paper Series, n.40, p.1-26, 2000.

NAKANE, M. I.; ROCHA, B. Concentração, concorrência e rentabilidade no setor bancário brasileiro: uma visão atualizada. São Paulo: [s.n.], 2010. (Tendências: Consultoria Integrada). Disponível em: .

http://www.febraban.org.br/7Rof7SWg6qmyvwJcFwF7I0aSDf9jyV/sitefebraban/Concorr\%EAncia_201 0_02_08.pdf. Acesso em: 15 set. 2012. 
STIGLITZ, J. E. e WEISS, A., Credit Rationing in Markets with Imperfect Information, The American Economic Review, Vol. 71, n. 3, p. 393-410, Jun.1981.

STOCK., J. H.; WATSON, M. W., Econometria. São Paulo: Addison Wesley, 2004.

TAYLOR, J. B. The Monetary Transmission Mechanism: An Empirical Framework. Journal of Economic Perspective. American Economic Association, v. 9, n. 4, p. 11-26, 1995.

TOOLSEMA, L. A.; STURM, J. E.; HAAN, J. de, Convergence of Monetary Transmission in EMU New Evidence. CESifo Working Papers n. 465, 2001.

WETH, M. A. The Pass-Through from Market Interest Rates to Bank Lending Rates in Germany. Banco Central da Alemanha, Centro de Pesquisa Econômica, Texto para discussão, n.11, v.02, 2002. 